Original Research Paper

\title{
Perceived Social Support and Opinions on Poverty: Is it Chronic or Transient?
}

\author{
Maurizio Norcia and Antonella Rissotto \\ Institute of Cognitive Sciences and Technologies-National Research Council, Via San Martino Della Battaglia, Rome, Italy
}

Article history

Received: 01-10-2014

Revised 07-10-2014

Accepted 03-01-2015

Corresponding Author:

Maurizio Norcia,

Institute of Cognitive Sciences

and Technologies-National

Research Council

Via San Martino Della Battaglia,

Rome, Italy

Tel: +3906 44595237

Fax: +3906 44595243

E-mail: maurizio.norcia@istc.cnr.it

\begin{abstract}
This article discusses the relation between perceptual component of social support and the beliefs about stability of poverty condition. To what extent individual's perception about having back covered, resulting from opinion about family's or friends' resources or their moral support, influences his belief about poverty as a chronic or a transient condition? Analyses-Chi ${ }^{2}$ test on bivariate crossings-have been carried out on a sample of 992 individuals resident in Lazio, an Italian region. They were asked to respond to a multidimensional semi-structured questionnaire on their social-economic status and beliefs about poverty. Outcomes emerged revealed a relation between the feeling safe thanks to personal supportive network and opinion on poverty: Respondents showing a greater feeling of back covered consider poverty a chronic condition more than others. On the contrary, the evaluation of poverty as a condition that is possible to escape from is more frequent among people who reported to feel morally supported or they can count on family's or friends' resources.
\end{abstract}

Keywords: Transient Poverty, Chronic Poverty, Poverty Beliefs, Perceived Social Support

\section{Introduction}

Poverty is a phenomenon that increasingly attracts Institutions' and scholars' attention. In September 2000, 189 Countries convened at UN in New York and subscribed "Millennium Declaration" (UN, 2000) in which a series of objectives was listed. "Millennium Development Goals" were aimed at building a "more peaceful, prosperous and just world" (ivi) and to reduce number of people living in poverty.

European Council, more or less contemporarily, has vested European Union in the task of eradicating poverty and fighting social exclusion in EU countries. Furthermore, European Union has declared 2010 the "Year for contrasting Poverty and social exclusion".

So, in these early years of 3rd millennium, political institutions appear to go into action against poverty, misery, extreme disparities and violations of human dignity. These actions, although important and desirable, prove how persistence of these phenomena represents a heavy responsibility for all societies and the concern they arouse.

Poverty and deprivation are multidimensional phenomena, difficult to understand and-therefore-to contrast. Methods for summarize different indicators in a summary aggregate statistic have long been the focus of inquiry, because they encompass various facets of people's life, such as economic dimension-(lack of) income or assets-but also psychological and social aspects. In the last decades a huge, increasing number of studies have emphasized how, for instance, a poor social capital, or scarce sense of control, people's perceptions and representations may be part of a deprived condition (Jain and Com, 2014; Bradshaw, 2007; Norcia and Rissotto, 2012; Norcia et al., 2010; Hunt, 2002).

As well as in abundance of indicators (for a review, Deaton, 1997; Anand and Harris, 1994; Ravallion, 1994), complexity of studying Poverty lie in adopting a temporal perspective: Is equally important, indeed, considering the time frame over which the indicators are observed, tracking longitudinally the unit of observation. Although the literature on dynamics of poverty is very thin (Baulch and Hoddinott, 2000), studying this aspect appears to be definitely relevant, due to three main reasons: First, focusing on process of impoverishment allows adequately assessing temporary non-poverty (i.e., for a lucky event Scott, 2000). This way, you may better tell the poor at all 
dates from the sometimes poor, that is people making in and out from poverty, which are usually much more numerous. But mainly this permits to take the perspective of the process and, consequently, to focus on vulnerability to poverty. Furthermore, this will also allow avoiding under/overestimations due to statistical artifacts (Deaton, 1997).

Second, observing the factors causing poverty/allowing to escape from poverty helps detecting adequate protection networks. Eventually, understanding how households better/worsen their conditions on the long-term (i.e., the extent to which poverty is transmitted intergenerationally) allows defining policies for development.

One of the main protection networks, according to literature, is constituted by the "perceived or actual instrumental and/or expressive provisions supplied by the community, social networks and confiding partners" (Lin, 1986), that is social support.

Shumaker and Brownell (1984) define social support as "an exchange of resources between at least two individuals perceived by the provider or the recipient to be intended to enhance the well-being of the recipient" (p. 13).

As stated, social support operates mainly when someone is helped to cope with a stressful situation by people belonging to his social network. As affirmed by Thoits (1986), intervention may be put into effect changing the situation itself (that is providing specific, practical solution), helping the person to change the meaning she attributes to the situation or, third, altering the person's affective response to the stress.

Apart from the above-mentioned ways in which social support takes shape, it has a powerful impact on various relevant dimension of individual's life. For instance, Hogan et al. (2002) and Rhodes (2004) highlight the positive influence of supportive families or friends on people's health status and on speed of recovery. This occurs both directly and indirectly through some cognitive mechanisms, coping strategies and health behaviors (Hammed, 2008; Salami, 2007; Karademas, 2006; Wills and Fegan, 2001; Davis and Swan, 1999).

Perceived social support was also studied as a mediating variable. For instance, Optimism or Self-efficacy were related to health through a strong sense of support (Karademas, 2006).

Furthermore, social support is operationalized in several different ways. Pierce et al. (1996) distinguishes among perceived social support (the belief that an adequate support would be available if it was needed), social embeddedness (the network of significant others that individual may count on within their social environment) and enacted social support (what significant others concretely do to support individual) (Abrar and Ghouri, 2010).
Reblin and Uchino (2008) distinguish between structural and functional components of support. The first refers to being a part of social networks or the measure of individual's participation. The second component focuses on transactions among individuals, such as favors, material aid or other type of active support.

If social embeddedness, enacted, structural and functional support are related to concrete, "tangible" aspects, perception of support is equally important in terms of coping with stress (Sarason et al., 1983) and is defined as the extent to which individuals believe that their needs for these aspects are fulfilled (Procidano and Heller, 1983) and requirements of social relationships are available within their network (Batool and Ahmad, 2013). Individuals "check" this availability usually considering family members, friends and significant others (Armstrong et al., 2005; Hale et al., 2005). Distinction among these various sources of support is important, because the same individual, e.g., at different periods of his life, may rely on family support or on friends to different extents. Furthermore, friend relationships have usually shorter duration than family relationships and require more commitment and competence to be maintained, since family relationships are, by definition, ours by birth (Procidano and Heller, 1983).

Procidano and Heller (1983) (ivi) have accurately observed that perceived support and support provided by networks are not identical: As deducible, perception of support is influenced by specific characteristics of the individual, temporal changes in attitude or mood as well as long-standing traits. Otherwise perceived support highly correlates with individual's psychological well-being and his vulnerability to poverty (Batool and Ahmad, 2013). People perceiving their social networks as really supportive if and when needed display lower levels of distress and depressive symptoms in response to stressors than others (Cohen, 2004; Lin, 1986; Thoits, 1995). Several authors have even found that perceived social support works as a better predictor of psychological status than structural/functional social support (Barrera Jr. and Garrison-Jones, 1992; Sarason et al., 1983; Schaefer et al., 1981).

\section{Objectives and Methods}

In this study data collected under a project granted by Lazio Council have been analyzed. The aim of the project was to gather information about the social-economic condition of people living in Lazio (Italy), by adopting a concept of poverty as multidimensional and dynamic deprivation ascribable to social and economic conditions (the inclusion/exclusion in relation to the job market and to the family social network of reference) and to psychological-motivational dimensions (such as attributive style, life goals and 
trouble in achieving them (Norcia and Rissotto, 2012; Norcia et al., 2012).

Specific objective of this study is to discuss the relation among perceived social support and opinion on poverty as a chronic/transient condition: Is perception of having back covered related to considering poverty as a condition you can escape from or as a chronic situation that cannot change, although individual's efforts or welfare interventions?

\section{The Questionnaire}

A semi-structured questionnaire was used. Its items were referable to thematic areas of social demographic information, occupational status, income, housing conditions, sense of security related to possession of assets, debt, economic status, difficulty, supporting networks, opinions and subjective experience Table 1.

\section{The Sample}

The sample, consisting of about 992 adults residing in Lazio, was stratified by three socio-demographic variables: Population size of municipality of residence, sex and age. The strata were calculated by census data collected by the ISTAT (2011).

In the table below (Table 2), main socio-demographic data are shown.

\section{Results}

\section{Index of Perceived Social Support}

The Index of perceived social support combines in an additional way two items of the questionnaire, related to individual's perception of moral support obtained from family/friends ("How often you feel moral support from your relatives/friends?") and his opinion about family/friends' possession of adequate resources to help him ("Do you think your relatives/friends own adequate resources to help you?"). Outcomes of building the Index have been categorized into three levels: "Never/seldom"; "Sometimes"; "Often/very often". The number of categories has been chosen in order to adequately convey the specificity of people's responses, but also to make differences sharply emerge (Table 3).

Outcomes obtained by crossing index of perceived social support from family with opinion about poverty has a weak statistical significance $(p<0.087)$. Observing the chart (Fig. 1 and 2), although the results of the $\mathrm{Chi}^{2}$ test, a trend clearly emerges: As the individual perceives he can count on his family's help, he increasingly considers poverty as a transient condition (Table 4 and 6). On the contrary, as respondents declare they could "sometimes" or "never/seldom" rely on support from their relatives, they more and more consider poverty as a chronic condition.

Table 1. The questionnaire

\begin{tabular}{lll}
\hline Concepts & Conceptual dimensions & Indicators \\
\hline $\begin{array}{l}\text { Sociodemographic, economic } \\
\text { and psychological dimensions }\end{array}$ & Demographic & Age \\
& Sex & Marital Status \\
& Psychological & Subjective perception of personal economic condition \\
& Opinion about chronicity/transience of poverty \\
& Aims and troubles in achieving them
\end{tabular}

Table 2. The sample

\begin{tabular}{|c|c|c|c|c|c|c|c|c|c|c|c|c|}
\hline & \multicolumn{3}{|c|}{ Education $^{1}$} & \multicolumn{6}{|c|}{ Age (years) } & \multicolumn{2}{|l|}{ Sex } & \multirow[b]{2}{*}{ Total } \\
\hline & Low & Mid & High & $0-24$ & $25-34$ & $35-44$ & $45-54$ & $55-64$ & $65+$ & $\mathrm{M}$ & $\mathrm{F}$ & \\
\hline $\mathrm{N}$ & 390 & 421 & 181 & 108 & 172 & 190 & 154 & 143 & 225 & 478 & 514 & 992 \\
\hline$\%$ & 39,3 & 42,4 & 18,2 & 10,9 & 17,3 & 19,1 & 15,5 & 14,4 & 22,7 & 48,1 & 51,9 & 100 \\
\hline
\end{tabular}

${ }^{\mathrm{T}}$ Education levels: Low (primary and middle school); Mid (high school); High (degree and post-degree) 
Table 3. Index of perceived social support from family* opinion on poverty

\begin{tabular}{|c|c|c|c|c|c|c|}
\hline & & & \multicolumn{3}{|c|}{ Index of perceived social support (family) } & \multirow[b]{2}{*}{ Total } \\
\hline & & & Never/seldom & Sometimes & Often/very often & \\
\hline \multirow{6}{*}{$\begin{array}{l}\text { "Do you think } \\
\text { poverty is..." }\end{array}$} & Chronic & Observed frequencies & 23 & 64 & 72 & 159 \\
\hline & & Expected frequencies & 15,5 & 66,5 & 77,1 & \\
\hline & & $\Delta \% \%^{2}$ & 48,6 & $-3-7$ & $-6,6$ & \\
\hline & Transient & Observed frequencies & 72 & 344 & 401 & 817 \\
\hline & & Expected frequencies & 79,5 & 341,5 & 395,9 & \\
\hline & & $\Delta \%$ & $-9,5$ & 0,7 & 1,3 & \\
\hline Total & & & 95 & 408 & 473 & 976 \\
\hline
\end{tabular}

Table 4. Chi $^{2}$ test

\begin{tabular}{llll}
\hline & Value & df & Asymptotic significance (two tailed) \\
\hline Pearson $\mathrm{Chi}^{2}$ & 4,875 & 2 &, 087 \\
Likelihood ratio & 4,426 & 2 &, 109 \\
Linear-linear association & 2,750 & 1 &, 097 \\
$\mathrm{~N}$ & 976 & & \\
\hline${ }^{2}$ Varian
\end{tabular}

${ }^{2}$ Variance (percentage) between observed frequency and expected frequency

Table 5. Index of perceived social support from friends * opinion on poverty

\begin{tabular}{|c|c|c|c|c|c|c|}
\hline & & & \multicolumn{4}{|c|}{ Index of perceived social support (friends) } \\
\hline & & & Never/seldom & Sometime & Often/very often & Total \\
\hline \multirow{6}{*}{$\begin{array}{l}\text { "Do you think } \\
\text { poverty is..." }\end{array}$} & Chronic & Observed frequencies & 58 & 75 & 22 & 155 \\
\hline & & Expected frequencies & 37,4 & 90,3 & 27.3 & \\
\hline & & $\Delta \%$ & 55,2 & $-17,0$ & $-19,4$ & \\
\hline & Transient & Observed frequencies & 172 & 481 & 146 & 799 \\
\hline & & Expected frequencies & 192,6 & 465,7 & 140,7 & \\
\hline & & $\Delta \%$ & $-10,7$ & 3,3 & 3,8 & \\
\hline Total & & & 230 & 556 & 168 & 954 \\
\hline
\end{tabular}

Table 6. Chi ${ }^{2}$ test

\begin{tabular}{llll}
\hline & Value & df & Asymptotic significance (two tailed) \\
\hline Pearson $\mathrm{Chi}^{2}$ & 17,935 & 2 &, 000 \\
Likelihood ratio & 16,587 & 2 &, 000 \\
Linear-linear association & 12,525 & 1 &, 000 \\
$\mathrm{~N}$ & 954 & & \\
\hline
\end{tabular}

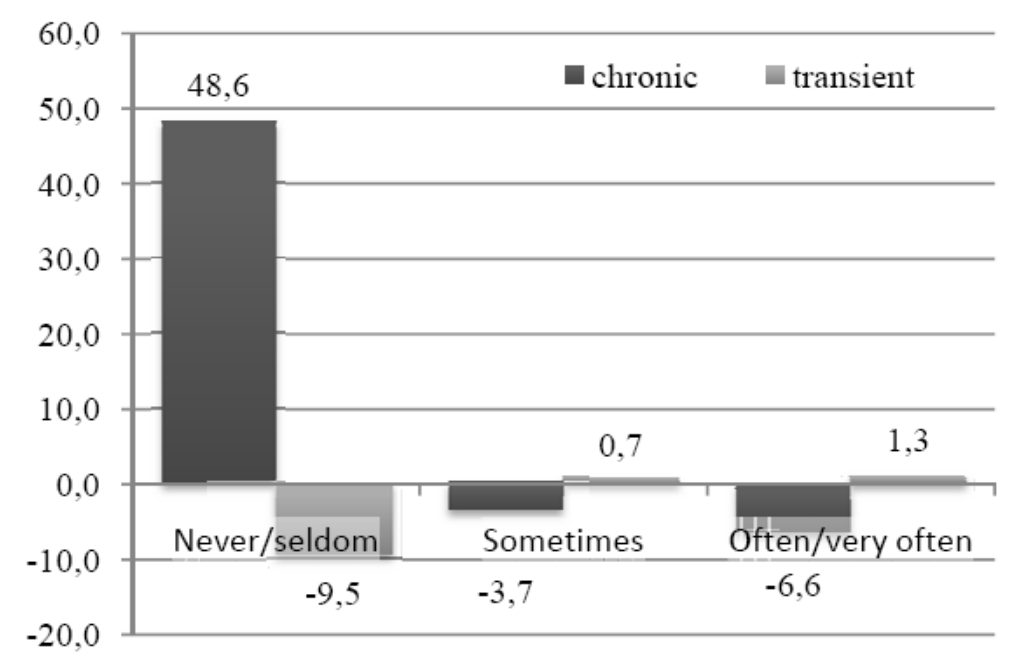

Fig. 1. Index of perceived social support from family* opinion on poverty 


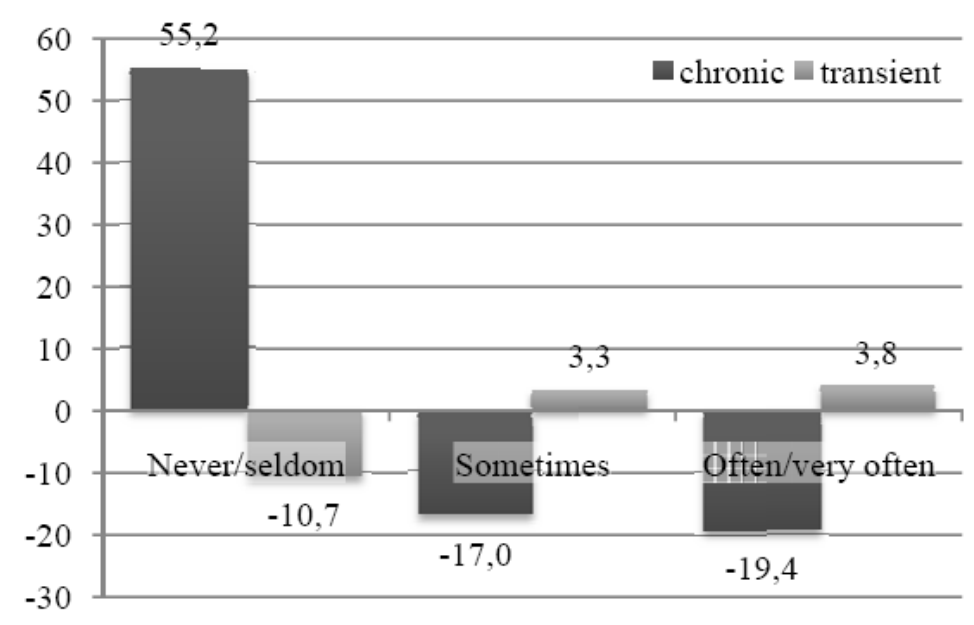

Fig. 2. Index of perceived social support from friends* opinion on poverty

As shown in Table 5, outcomes of this analysis seem to be coherent with the trend emerged in the previous analysis: People who perceive the opportunity to rely on an adequate aid from friends, consider more frequently poverty as a transient condition than others do. On the other hand, who believes he can't count on a possible help from his friends, more often thinks that poverty is a condition you can't escape from.

\section{Discussion and Conclusion}

This research has been carried out with the aim of examining in depth opinions towards the chronicity/transience of poverty, also considered the scarce number of studies, to our knowledge, that relate these opinions with psychological, social or economic characteristics of respondents. We have specifically focused on perception of having back covered, that is subjective assessment of family's and friends' resources, their possible willingness to help the respondent and the moral support they provide to him (according to his perception).

Analyses we have conducted have confirmed that this relation seems to make sense: People feeling that they can rely on moral or material support from their families or friends think more frequently that poverty may be a transient condition. On the contrary, feeling less morally supported or less "safe" seems to be related to thinking that people generally can't emancipate from.

\section{Two Possible Explanations Could be Suggested}

First explanation is related to the perception of having back-covered, the overall feeling of safety that improves people's well-being (Murphy et al., 2010; Kawachi and Berkman, 2001; Dehle et al., 2001) several studies (Chang and Sanna, 2001, Diener et al., 2003; Eid and Diener, 2004; Makikangas and Kinnunen,
2003; Singh, 2014) have found that optimism significantly predicts several aspects of subjective wellbeing, highlighting the circularity of the relation between well-being and optimism and influences the way they perceive the world around them: "Everything sounds rosy", they see things in an optimistic light, seem to employ more problem-focused coping strategies (Taylor and Armor, 1996) and tend to expect positive outcomes even in the face of obstacles (Scheier and Carver, 1985). This could consequently influence people's perception of poverty as a transient rather than chronic condition.

Second explanation refers to a more cognitive level influenced-in some cases-by personal experience: Several exit strategies are perceived as more achievable because they have shown to be accessible for people well-supported by their social network. For instance, Brouwer et al. (2010) have found that return to work is more frequent for people feeling well-supported by family or friends. Hence, when people well/scarcely supported experience or perceive that a set of resources are/are not available, they will consequently tend to consider possible/impossible exit from poverty.

Further studies could examine in depth the relation between perceptual aspects of social support and opinions on stability of poverty. First, social support for economic difficulties in Italy is often exerted by families (the main social security cushion) and by non-public organizations (Catholic Church and other private-social agencies) and they are frequently more effective than public social services. The present study has not considered the specificity of this background and how it may influence the perception of social support owned by individuals. Similar studies carried out in other context will help to shine a light on the relation between support that individual perceives he may obtain by various subjects and his opinions about poverty. 


\section{Funding Information}

This study was under Research Grant supported by Institute of Cognitive Sciences and Technologies at Italian National Research Council.

\section{Conflict of Interest}

There is no conflict of interest.

\section{Author's Contributions}

All authors equally contributed in this work.

\section{Ethics}

This article is original and contains unpublished material. The corresponding author confirms that all of the other authors have read and approved the manuscript and no ethical issues involved.

\section{References}

Abrar, N. and A.M. Ghouri, 2010. Dual earners and balance in their family and work life: Findings from Pakistan. Eur. J. Soc. Sci., 17: 28-40.

Anand, S. and C.J. Harris, 1994. Choosing a welfare indicator. Am. Econ. Rev., 84: 226-231.

Armstrong, M.I., S. Birnie and M.T. Ungar, 2005. Pathways between social support, family well being, quality of parenting and child resilience: What we know. J. Child Family Stud., 14: 269-281. DOI: $10.1007 / \mathrm{s} 10826-005-5054-4$

Barrera Jr, M. and C. Garrison-Jones, 1992. Family and peer social support as specific correlates of adolescent depressive symptoms. J. Abnormal Child Psychol., 20: 1-16. DOI: 10.1007/BF00927113

Batool, S. and A. Ahmad, 2013. Impact of perceived social support on psychological well-being of teenagers. Sci. J. Psychol. DOI: 10.7237/sjpsych/267

Baulch, B. and J. Hoddinott, 2000. Economic mobility and poverty dynamics in developing countries. J. Dev. Stud., 36: 1-24. DOI: 10.1080/00220380008422652

Bradshaw, T.K., 2007. Theories of poverty and anti-poverty programs in community development. Community Dev., 38: 7-25. DOI: 10.1080/15575330709490182

Brouwer, S., M.F. Reneman, U. Bültmann, J.J. Van der Klink and J.W. Groothoff, 2010. A prospective study of return to work across health conditions: Perceived work attitude, self-efficacy and perceived social support. J. Occupat. Rehabilit., 20: 104-112. DOI: $10.1007 / \mathrm{s} 10926-009-9214-\mathrm{z}$

Chang, E.C. and L.J. Sanna, 2001. Optimism, pessimism and positive and negative affectivity in middle-aged adults: A test of a cognitive-affective model of psychological adjustment. Psychol. Ag., 16: 524531. DOI: 10.1037/0882-7974.16.3.524
Cohen, S., 2004. Social relationships and health. Am. Psychol., 59: 676. DOI: 10.1037/0003-066X.59.8.676

Davis, M.C. and P.D. Swan, 1999. Association of negative and positive social ties with fibrinogen levels in young women. Health Psychol., 18: 131139. PMID: 10194048

Deaton, A., 1997. The Analysis of Household Surveys: A Microeconometric Approach to Development Policy. 1st Edn., World Bank Publications, Baltimore, ISBN-10: 0801852544, pp: 479.

Dehle, C., D. Larsen and J.E. Landers, 2001. Social support in marriage. Am. J. Family Therapy, 29: 307-324. DOI: 10.1080/01926180126500

Diener, E., S. Oishi and R.E. Lucas, 2003. Personality, culture and subjective well-being: Emotional and cognitive evaluations of life. Ann. Rev. Psychol., 54: 403-425.

DOI: 10.1146/annurev.psych.54.101601.145056

Eid, M. and E. Diener, 2004. Global judgments of subjective well-being: Situational variability and long-term stability. Soc. Indicat. Res., 65: 245-277. DOI: 10.1023/B:SOCI.0000003801.89195.bc

Hale, C.J., J.W. Hannum and D.L. Espelage, 2005. Social support and physical health: The importance of belonging. J. Am. Coll. Health, 53: 276-284. DOI: $10.3200 / \mathrm{JACH} .53 .6 .276-284$

Hammed, A., 2008. The interactive effect of stress, social support and work-family conflict on Nigerian women's mental health. Eur. J. Soc. Sci., 7: 53-65.

Hogan, B.E., W. Linden and B. Najarian, 2002. Social support interventions: Do they work? Clin. Psychol. Rev., 22: 381-440. DOI: $10.1016 / \mathrm{S} 0272-7358(01) 00102-7$

Hunt, M.O., 2002. Religion, race/ethnicity and beliefs about poverty. Soc. Sci. Q., 83: 810-831. DOI: $10.1111 / 1540-6237.00116$

ISTAT, 2011. Censimento generale della popolazione e delle abitazioni. Istituto Nazionale di Statistica.

Jain, A. and M. Com, 2014. The mandatory CSR in India: A boon or bane. Ind. J. Applied Res., 4: 301-304.

Karademas, E.C., 2006. Self-efficacy, social support and well-being: The mediating role of optimism. Personality Individual Differences, 40: 1281-1290. DOI: 10.1016/j.paid.2005.10.019

Kawachi, I. and L.F. Berkman, 2001. Social ties and mental health. J. Urban Health, 78: 458-467. PMID: 11564849

Lin, N., 1986. Conceptualizing Social Support. In: Socio/Support, Fife Events and Depression, Lin, N.., A. Dean and W. Ensel (Eds.), Academic Press, Orlando, Florida, pp: 17-30.

Makikangas, A. and U. Kinnunen, 2003. Psychosocial work stressors and well-being: self-esteem and optimism as moderators in a one-year longitudinal sample. Personality Individual Differences, 35: 537-557. DOI: 10.1016/S0191-8869(02)00217-9 
Murphy, G.C., M.A. O'Hare and L. Wallis, 2010. The relationships among different types of social support accessed by traumatic spinal cord injury survivors. Int. J. Disability Manage., 5: 59-66. DOI: $10.1375 / \mathrm{jdmr} .5 .2 .59$

Norcia, M. and A. Rissotto, 2012. Social perception and attribution of causality for poverty: Which is the influence of thinking to myself or to others. Proceedings of the 2nd International Conference on Applied Social Science (ASS' 12), Information Engineering Research Institute, Newark.

Norcia, M., A. Castellani and A. Rissotto, 2010. The process of causal attribution of poverty: Preliminary results of a survey in Italy. OIDA Int. J. Sustainable Dev., 1: 85-97.

Norcia, M., A. Rissotto and E. Noci, 2012. Measuring poverty through capabilities: Preliminary results of a research in Italy. OIDA Int. J. Sustainable Dev., 4: 39-46.

Pierce, G.R., B.R. Sarason, I.G. Sarason, H.J. Joseph and C.A. Henderson, 1996. Conceptualizing and Assessing Social Support in the Context of the Family. In: Handbook of Social Support and the Family, Pierce, G.R., B.R. Sarason and I.G. Sarason (Eds.), Springer, pp: 3-23.

Procidano, M.E. and K. Heller, 1983. Measures of perceived social support from friends and from family: Three validation studies. Am. J. Community Psychol., 11: 1-24. DOI: 10.1007/BF00898416

Ravallion, M., 1994. Poverty comparisons. Taylor and Francis.

Reblin, M. and B.N. Uchino, 2008. Social and emotional support and its implication for health. Curr. Opin. Psychiatry, 21: 201-205. DOI: $10.1097 /$ YCO.0b013e3282f3ad89

Rhodes, J.E., 2004. Family, Friends and Community: The Role of Social Support in Promoting Health. In: Clinical Handbook of Health Psychology: A Practical Guide to Effective Interventions, Camic, P.M. and S.J. Knight (Eds.), Hogrefe and Huber Publishers, ISBN-10: 0889372608.
Salami, S.O., 2007. Multiple role strain and Nigerian working mothers' psychological well-being: Do selfefficacy, coping strategies and social support make a difference. Eur. J. Soc. Sci., 5: 43-53.

Sarason, I.G., H.M. Levine, R.B. Basham and B.R. Sarason, 1983. Assessing social support: The social support questionnaire. J. Personality Soc. Psychol., 44: 127-139. DOI: 10.1037/0022-3514.44.1.127

Schaefer, C., J.C. Coyne and R.S. Lazarus, 1981. The health-related functions of social support. J. Behav. Med., 4: 381-406. DOI: 10.1007/BF00846149

Scheier, M.F. and C.S. Carver, 1985. Optimism, coping and health: Assessment and implications of generalized outcome expectancies. Health Psychol., 4: 219. DOI: 10.1037/0278-6133.4.3.219

Scott, C.D., 2000. Mixed fortunes: a study of poverty mobility among small farm households in Chile, 1968-86. J. Dev. Stud., 36: 155-180. DOI: $10.1080 / 00220380008422658$

Shumaker, S.A. and A. Brownell, 1984. Toward a theory of social support: Closing conceptual gaps. J. Soc. Issues, 40: 11-36. DOI: 10.1111/j.1540-4560.1984.tb01105.x

Singh, J., 2014. Stress among marketing executives: A review of literature for conceiving a conceptual model and structuring a scale for measurement of stress. Ind. J. Applied Res.

Taylor, S.E. and D.A. Armor, 1996. Positive illusions and coping with adversity. J. Personality, 64: 873898. DOI: 10.1111/j.1467-6494.1996.tb00947.x

Thoits, P.A., 1986. Social support as coping assistance. J. Consult. Clin. Psychol., 54: 416. DOI: $10.1037 / 0022-006 X .54 .4 .416$

Thoits, P.A., 1995. Stress, coping and social support processes: Where are we? What next? J. Health Soc. Behav., 53-79. DOI: 10.2307/2626957

UN, 2000. Resolution adopted by the General Assembly. United Nations.

Wills, T.A. and M.F. Fegan, 2001. Social Networks and Social Support. In: Handbook of Health Psychology, Baum, A., T.A. Revenson and J.E. Singer (Eds.), Erlbaum, Mahwah, NJ., ISBN-10: 0805814957, pp: 209-234. 